\title{
Timely recognition of acute coronary occlusion in patients presenting without ST-segment elevation: a major clinical challenge. Author's reply
}

\author{
Konstantinos C Theodoropoulos', Antonios Ziakas', Nikolaos PE Kadoglou², George Kassimis'1,2 \\ ${ }^{1} 1^{\text {st }}$ Cardiology Department, University General Hospital AHEPA, Aristotle University of Thessaloniki, Thessaloniki, Greece \\ ${ }^{2} 2^{\text {nd }}$ Cardiology Department, Hippokration Hospital, Thessaloniki, Greece
}

\author{
Correspondence to: \\ Konstantinos C \\ Theodoropoulos, MD, MSC \\ $1^{\text {st }}$ Cardiology Department, \\ University General Hospital \\ AHEPA, \\ 1 Stilponos Kyriakidi Street, \\ 54636, Thessaloniki, Greece, \\ phone: +30 2310994830, \\ e-mail: \\ ktheod2005@hotmail.com \\ Copyright by the \\ Author(s), 2021 \\ Kardiol Pol. 2021: \\ 79 (7-8): 899-900; \\ DOl: 10.33963/KP.a2021.0050 \\ Received: \\ June 21, 2021 \\ Revision accepted: \\ June 21, 2021 \\ Published online: \\ June 27, 2021
}

Acute coronary occlusion, when prolonged, leads to irreversible myocardial necrosis, reduced left ventricular systolic function, and poor clinical outcomes. Timely recognition of the full spectrum of patients presenting with suspected acute myocardial infarction (AMI) who have acute coronary occlusion remains a major clinical challenge [1].

Current guidelines do not recommend routine emergent angiography and revascularization for the patients with suspected non-ST elevation myocardial infarction (NSTEMI) at presentation since the absence of ST-segment elevation is supposed to indicate a lack of total epicardial coronary occlusion and therefore does not warrant emergency myocardial reperfusion [2]. NSTEMI patients initially undergo risk stratification and referral for an early invasive strategy based on age, troponin elevation, electrocardiogram (ECG) changes, and clinical/hemodynamic status [2]. Given that NSTEMI incidence increases, and considering the fact that despite contemporary management there remains unmet clinical need to reduce adverse cardiovascular events in this patient population, improved identification of the high-risk patients who may benefit from expedited angiography and revascularization is needed. The subgroup of patients with suspected NSTEMI who have acute coronary occlusion falls into this category [1].

There is a broad spectrum of 12-lead surface ECG changes, other than classical ST-segment elevation, that can accompany acute coronary occlusion and clinicians need to be aware of those. ST-segment elevation in lead aVR, the De Winter pattern, the Wellens' sign, and ST depression in precordial leads V1-V3 represent high risk ECG patterns suggestive of acute cor- onary occlusion [1]. Adjunctive imaging with bedside echocardiography [3] and monitoring with serial ECGs [4] have been proposed to improve sensitivity for acute coronary occlusion diagnosis.

Our case report of a young man who presented with chest pain and an ECG showing hyperacute $T$ waves in leads V1-V3 and the de Winter pattern in leads V4-V5 represents a classic example where atypical ECG patterns can cause confusion to the clinician and lead to false therapeutic pathways. Whether this ECG pattern represents a combination of two different ECG patterns (de Winter and hyperacute $T$ waves) or an atypical de Winter sign, as Yalta et al. believe [5], is difficult to say. However, someone can easily realize that nowadays, in the era of multiple emerging sophisticated cardiac tests, even though the ECG does not appear so 'exciting', it still represents a very useful bedside diagnostic tool for the clinicians, and thorough analysis of it is a prerequisite for good clinical practice.

Collection and big data analysis of the globally massive number of ECGs that are digitally acquired in patients with suspected ACS who subsequently undergo coronary angiography and application of deep learning algorithms would possibly lead to an efficacious identification of those patterns (such as the de Winter sign and its atypical forms) that are associated with acute coronary occlusion [1].

\section{Article information}

Conflict of interest: None declared.

Open access: This article is available in open access under Creative Common Attribution-Non-Commercial-No Derivatives 4.0 International (CC BY-NC-ND 4.0) license, allowing to download articles and share them 
with others as long as they credit the authors and the publisher, but without permission to change them in any way or use them commercially. For commercial use, please contact the journal office at kardiologiapolska@ptkardio.pl.

How to cite: Theodoropoulos KC, Ziakas A, Kadoglou N, et al. Timely recognition of acute coronary occlusion in patients presenting without ST-segment elevation: a major clinical challenge. Author's reply. Kardiol Pol. 2021; 79(7-8): 899-900, doi: 10.33963/KP.a2021.0050.

\section{REFERENCES}

1. De Silva R, Steg PG. Identifying patients with acute total coronary occlusion in NSTEACS: finding the high-risk needle in the haystack. Eur Heart J. 2017; 38(41): 3090-3093, doi: 10.1093/eurheartj/eh×520, indexed in Pubmed: 29020408.
2. Collet JP, Thiele H, Barbato E, et al. 2020 ESC Guidelines for the management of acute coronary syndromes in patients presenting without persistent ST-segment elevation. Rev Esp Cardiol (Engl Ed). 2021; 74(6): 544, doi: 10.1016/j.rec.2021.05.002, indexed in Pubmed: 34020768.

3. Sabia $\mathrm{P}$, Afrookteh A, Touchstone DA, et al. Value of regional wall motion abnormality in the emergency room diagnosis of acute myocardial infarction. A prospective study using two-dimensional echocardiography. Circulation. 1991; 84(3 Suppl): 185-192, indexed in Pubmed: 1884510.

4. Theodoropoulos KC, Ziakas A, Kadoglou NPE, et al. Combination of hyperacute T waves and de Winter sign in precordial leads: a hybrid pattern equivalent to ST-segment elevation? Kardiol Pol. 2021; 79(4): 477-478, doi: 10.33963/KP.15926, indexed in Pubmed: 33843177.

5. Yalta K, Ozkan U, Yetkin E. Atypical patterns of de Winter sign: Even more confusion in clinical practice. Kardiol Pol. 2021, doi: 10.33963/KP.a2021.0049, indexed in Pubmed: 34176115. 